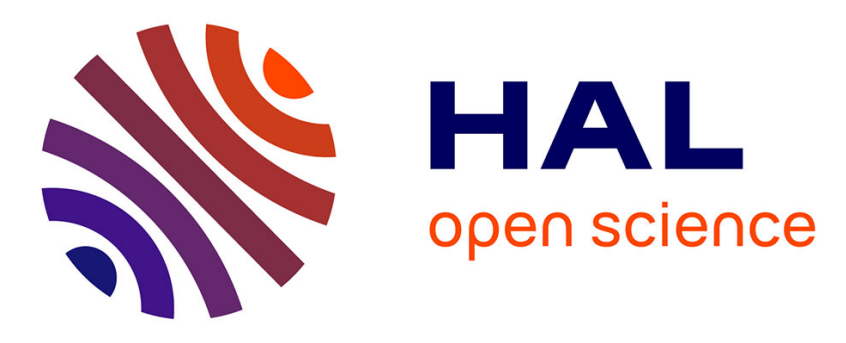

\title{
The role of ion-molecule reactions in the growth of heavy ions in Titan's ionosphere
}

J. H. Westlake, J. H. Waite Jr., Nathalie Carrasco, Murielle Richard, T.

Cravens

\section{- To cite this version:}

J. H. Westlake, J. H. Waite Jr., Nathalie Carrasco, Murielle Richard, T. Cravens. The role of ionmolecule reactions in the growth of heavy ions in Titan's ionosphere. Journal of Geophysical Research Space Physics, 2014, 119 (7), pp.5951-5963. 10.1002/2014JA020208 . hal-01023872

\section{HAL Id: hal-01023872 \\ https://hal.science/hal-01023872}

Submitted on 9 Jul 2020

HAL is a multi-disciplinary open access archive for the deposit and dissemination of scientific research documents, whether they are published or not. The documents may come from teaching and research institutions in France or abroad, or from public or private research centers.
L'archive ouverte pluridisciplinaire HAL, est destinée au dépôt et à la diffusion de documents scientifiques de niveau recherche, publiés ou non, émanant des établissements d'enseignement et de recherche français ou étrangers, des laboratoires publics ou privés. 


\section{Journal of Geophysical Research: Space Physics}

\section{RESEARCH ARTICLE \\ 10.1002/2014JA020208 \\ The role of ion-molecule reactions in the growth of heavy ions in Titan's ionosphere}

Key Points:

- Ion-molecule reactions are responsible for the growth of Titan's heavy ions

- Titan's heavy ions are built from the atmospheric building blocks $\mathrm{C}_{2} \mathrm{H}_{2}$ and $\mathrm{C}_{2} \mathrm{H}_{4}$

- These ions are a source of heavy hydrocarbons observed throughout the atmosphere

Correspondence to:

J. H. Westlake,

Joseph.westlake@jhuapl.edu

\section{Citation:}

Westlake, J. H., J. H. Waite Jr., N. Carrasco, M. Richard, and T. Cravens (2014), The role of ion-molecule reactions in the growth of heavy ions in Titan's ionosphere, J. Geophys. Res. Space Physics, 119, 5951-5963, doi:10.1002/ 2014JA020208.

Received 22 MAY 2014 Accepted 10 JUL 2014 Accepted article online 13 JUL 2014 Published online 24 JUL 2014 and a total production rate for large molecules of $7.1 \times 10^{-16} \mathrm{~g} \mathrm{~cm}^{-2} \mathrm{~s}^{-1}$.

\author{
J. H. Westlake', J. H. Waite Jr. ${ }^{2}$, N. Carrasco ${ }^{3,4}$, M. Richard ${ }^{5,6}$, and T. Cravens ${ }^{5}$ \\ 'Johns Hopkins University Applied Physics Laboratory, Laurel, Maryland, USA, ${ }^{2}$ Space Science and Engineering Division, \\ Southwest Research Institute, San Antonio, Texas, USA, ${ }^{3}$ Université de Versailles St. Quentin, LATMOS, Pierre et Marie Curie, \\ CNRS, Guyancourt, France, ${ }^{4}$ Institut Universitaire de France, Paris, France, ${ }^{5}$ Department of Physics and Astronomy, \\ University of Kansas, Lawrence, Kansas, USA, ${ }^{6}$ Department of Physics and Astronomy, Benedictine College, Atchison, \\ Kansas, USA
}

Abstract The lon and Neutral Mass Spectrometer (INMS) and Cassini Plasma Spectrometer (CAPS) have observed Titan's ionospheric composition and structure over several targeted flybys. In this work we study the altitude profiles of the heavy ion population observed by the Cassini Plasma Spectrometer-lon Beam Spectrometer (CAPS-IBS) during the nightside T57 flyby. We produce altitude profiles of heavy ions from the C6-C13 group ( $C_{i}$ indicates the number, $i$, of heavy atoms in the molecule) using a CAPS-IBS/INMS cross calibration. These altitude profiles reveal structure that indicates a region of initial formation and growth at altitudes below $1200 \mathrm{~km}$ followed by a stagnation and dropoff at the lowest altitudes (1050 km). We suggest that an ion-molecule reaction pathway could be responsible for the production of the heavy ions, namely reactions that utilize abundant building blocks such as $\mathrm{C}_{2} \mathrm{H}_{2}$ and $\mathrm{C}_{2} \mathrm{H}_{4}$, which have been shown to be energetically favorable and that have already been identified as ion growth patterns for the lighter ions detected by the INMS. We contrast this growth scenario with alternative growth scenarios determining the implications for the densities of the source heavy neutrals in each scenario. We show that the high-mass ion density profiles are consistent with ion-molecule reactions as the primary mechanism for large ion growth. We derive a production rate for benzene from electron recombination of $\mathrm{C}_{6} \mathrm{H}_{7}^{+}$of $2.4 \times 10^{-16} \mathrm{~g} \mathrm{~cm}^{-2} \mathrm{~s}^{-1}$

\section{Introduction}

Titan's reducing upper atmosphere derives its free energy for its complex chemistry from the ionization and dissociation of the primary molecules $\mathrm{N}_{2}$ and $\mathrm{CH}_{4}$, which initiate the reaction processes leading to the formation of large hydrocarbons and nitrogen bearing molecules. Besides $\mathrm{N}_{2}$ and $\mathrm{CH}_{4}$, Titan's upper atmosphere consists of molecular hydrogen $\left(\mathrm{H}_{2}\right)$, acetylene $\left(\mathrm{C}_{2} \mathrm{H}_{2}\right)$, ethylene $\left(\mathrm{C}_{2} \mathrm{H}_{4}\right)$, hydrogen cyanide $(\mathrm{HCN})$, ethane $\left(\mathrm{C}_{2} \mathrm{H}_{6}\right)$, and a multitude of other molecules [Magee et al., 2009]. These molecules combine chemically through neutral and ion processes to form large hydrocarbons such as benzene $\left(\mathrm{C}_{6} \mathrm{H}_{6}\right)$ and toluene $\left(\mathrm{C}_{7} \mathrm{H}_{8}\right)$ [Waite et al., 2007].

Titan's upper atmosphere and ionosphere have been sampled by the instruments on board the Cassini spacecraft. The composition of the ions and neutrals has been determined for the most abundant species [Waite et al., 2005, 2007; Cravens et al., 2006; Vuitton et al., 2007; Magee et al., 2009; Cui et al., 2009a]. The lon and Neutral Mass Spectrometer (INMS) has observed the atmospheric composition down to about $950 \mathrm{~km}$ in altitude. Positive ion signals were clearly observed throughout the INMS mass range of 0-8 and 12-99 amu. The Cassini Plasma Spectrometer's lon Beam Spectrometer (CAPS-IBS) was used as a low-mass resolution ion mass spectrometer to observe ions with masses up to about $350 \mathrm{amu}$. [Waite et al., 2007; Crary et al., 2009]. Complementary to this observation is that of the Electron Spectrometer (CAPS-ELS) that found negative ions of mass up to about 10,000 amu. [Coates et al., 2007]. The chemistry and role of the large ions, both positive and negative, in Titan's upper atmosphere is largely unknown but has been postulated to be tightly coupled and interconnected [Waite et al., 2007; Lavvas et al., 2013].

The hydrocarbon chemistry at Titan has been shown to lead to the production of benzene $\left(\mathrm{C}_{6} \mathrm{H}_{6}\right)[$ Wilson et al., 2003; Waite et al., 2007; De La Haye et al., 2008]. There have been several attempts by the modeling community to reproduce the INMS-observed benzene abundances including those based solely on radical neutral and termolecular processes [Lebonnois, 2005], some ion-molecule reactions coupled with neutral 
processes [Wilson et al., 2003], and using intricately coupled ion-molecule chemical schemes [De La Haye et al., 2008]. The globally averaged molar fraction of benzene directly measured by the INMS was found to be $(2.48 \pm 0.11) \times 10^{-6}$ at $1050 \mathrm{~km}$ altitude [Magee et al., 2009]. The study of Vuitton et al. [2008] argues that most of the observed benzene is a product of reactions between phenyl radicals $\left(\mathrm{C}_{6} \mathrm{H}_{5}\right)$ and hydrogen within the INMS instrument's antechamber yielding an ambient benzene abundance one third that of the total observed peak level and implying that significant amounts of the phenyl radical are present in Titan's upper atmosphere. Regardless of interpretation, the Cassini INMS data show that the mixing ratio of benzene or benzene and phenyl is a few times $10^{-6}$ and indicating that the chemistry is efficient in producing not only unsaturated hydrocarbons but also aromatic hydrocarbons.

Crary et al. [2009] studied the CAPS-IBS spectra using a cross calibration with the INMS spectra for the T16-T40 flybys. This study fits the spectra using the spacecraft potential, ion temperature, along-track wind, and relative calibration coefficients as free parameters to produce a mass scale for the CAPS-IBS spectrum and thereby determine the densities of the ions observed. The high-mass ion abundances were found to increase exponentially with altitude down to the lowest observed Cassini altitudes. The chemical production mechanisms studied by Wilson et al. [2003] were compared to the observed peak locations, and it was proposed that the most probable compounds larger than benzene were aromatic in character. This analysis further supports the supposition that aromatic chemistry is efficient in Titan's ionosphere and that it is likely to produce compounds more complex than benzene. The chemistry leading to molecular growth at masses greater than benzene is largely unknown especially at the pressures and temperatures of the Titan ionospheric environment.

In this work we study in depth the altitude profiles of the large ions during the nightside T57 flyby. The T57 flyby was special because it had the CAPS actuator fixed throughout the flyby allowing for the continuous observation of the large ions. We utilize the cross calibration with the INMS instrument to produce altitude profiles of the large ion groups from the C6-C13 group where the $C_{i}$ notation indicates the number, $i$, of heavy atoms (carbon or nitrogen) included in the molecule. We analyze these altitude profiles to determine the process responsible for the production of these large ions and further assess their fate in the atmosphere.

\section{CAPS-IBS Data Reduction Method}

The CAPS-IBS instrument is fundamentally a curved-electrode electrostatic analyzer with three long and narrow $\left(150^{\circ}\right.$ by $\left.1.4^{\circ}\right)$ entrance apertures each tilted $30^{\circ}$ relative to the others [Young et al., 2004]. These three apertures or "fans" are arranged such that high-angular resolution 3-D velocity space measurements can be obtained. Positively charged ions enter these apertures and acquire trajectories, which are chords of conic sections defined by the central electric force field established between the inner spherical electrode and set at a negative potential with respect to the outer grounded spherical electrode. Ions within the allowed energy range follow the complete $178^{\circ}$ bend and are then detected by one of the channel-electron multiplier detectors placed at the exit of the analyzer. lons with energies or incident angles outside of the acceptable range are lost on impact with one of the electrodes. The energy resolution of the CAPS-IBS is $0.014(\Delta E / E)$, and the instrument sweeps over 255 adjacent energies ranging from 3 to $207 \mathrm{eV}$ every $2 \mathrm{~s}$ [Young et al., 2004]. The CAPS-IBS is on a rotationally actuated platform allowing for the sensor to scan through the phase space of the plasma. During the flybys T16-T51 the rotational actuator scanned at a cadence of $52 \mathrm{~s}$. During the T55-T59 flybys the actuator was fixed in the ram direction, allowing for measurements at a $2 \mathrm{~s}$ cadence.

Theoretically, the peak flux from a given species, $\alpha$, occurs at an energy

$$
E_{\alpha}=\frac{m_{\alpha} w^{2}}{2}+8 k T
$$

where $m_{\alpha}$ is the mass of species $\alpha, w$ is the flow speed, in this case it is primarily the spacecraft velocity of roughly $6 \mathrm{~km} / \mathrm{s}$, and $T$ is the ion temperature. When the flow speed is much larger than the thermal velocity (hypersonic flow), the energy in which a peak appears provides a measure of the mass of the ion. The energy spectra from the CAPS-IBS can then be used to produce mass spectra with a theoretical resolution of

$$
\frac{M}{\Delta M} \sim \frac{w}{\sqrt{2 k T / m_{\alpha}}} \sim 20\left(\text { at } m_{\alpha}=28\right)
$$




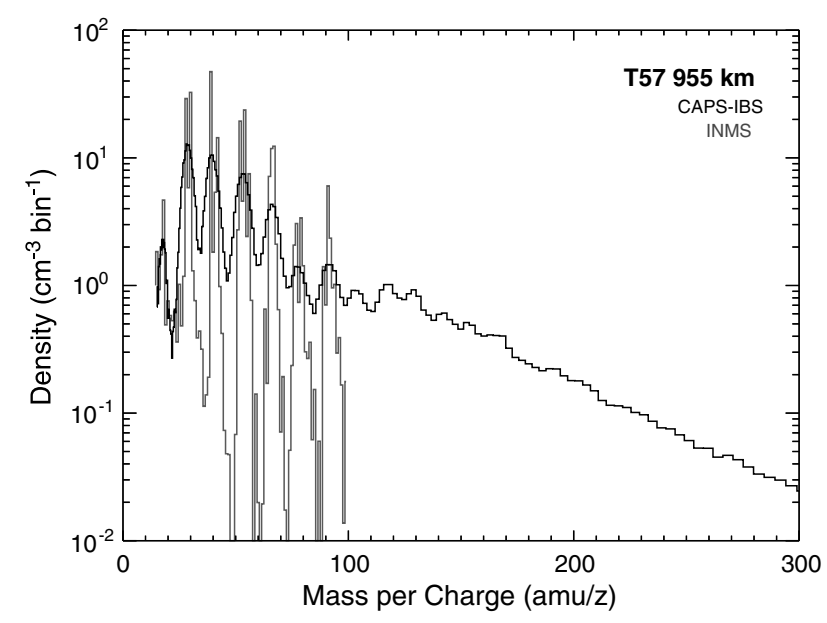

Figure 1. The CAPS-IBS and INMS mass spectra obtained at $955 \mathrm{~km}$ altitude during the T57 nightside flyby at $955 \mathrm{~km}$. The CAPS-IBS densities have been calculated using the INMS/CAPS-IBS cross calibration described in the text.
The Cassini spacecraft generally obtains a slight negative charge as it moves through Titan's ionosphere. This negative charge, along with any ion velocity vectors along the motion path of the spacecraft, will affect the energy at which an ion is detected. Using these factors to correct equation (1) gives

$$
E_{\alpha}=\frac{1}{2} m_{\alpha}\left(w_{\mathrm{SC}}+w_{\text {wind }}\right)^{2}+e \Phi_{\mathrm{SC}},
$$

where $w_{\mathrm{SC}}$ is the spacecraft velocity, $w_{\text {wind }}$ is the along-track wind velocity, and $\Phi_{\mathrm{SC}}$ is the spacecraft potential. The crosscalibration process consists of two steps: the first is to produce an accurate $m / z$ by correcting for the spacecraft potential and along-track wind velocity. In step two we calibrate the intensity of the CAPS-IBS data by fitting to the INMS data.

This study analyzes INMS and CAPS-IBS data from the T57 flyby (22 June 2009); we show one example of the CAPS-IBS data from this flyby in Figure 1. The peaks observed in the masses below 100 amu have been characterized by the Cassini INMS instrument [e.g., Waite et al., 2007]. Above 100 amu statistically significant peaks are observed up to the C13 group, and ions are clearly present past $300 \mathrm{amu}$, though no further peaks are evident. Crary et al. [2009] studied the peak locations of these high-mass ions and indicated that they were most likely aromatic in character due to their primary peak location.

Crary et al. [2009] analyzed the T16-T40 flybys using a procedure in which spectral data from the CAPS-IBS and INMS instruments are fit to a physical model of their respective response functions. The physical models utilize the ion temperature, spacecraft potential, and along-track winds as free parameters. This work utilizes the same physical instrument model as Crary et al. [2009]. Converting the counts from each sensor to fluxes directly compares the INMS ion spectra and CAPS-IBS spectra. The INMS ion densities from Mandt et al. [2012] are inserted into the CAPS-IBS instrument response function to produce a simulated CAPS-IBS degraded resolution spectrum of the INMS data. The INMS and CAPS-IBS fluxes are compared directly, and a $\chi^{2}$ goodness of fit statistic is determined. An initial fit is produced by minimizing the $\chi^{2}$ through a downhill simplex method using the spacecraft potential and amplitude correction as free parameters with a fixed initial temperature. This initial fit is then used as a starting point for subsequent fits. The procedure was tested
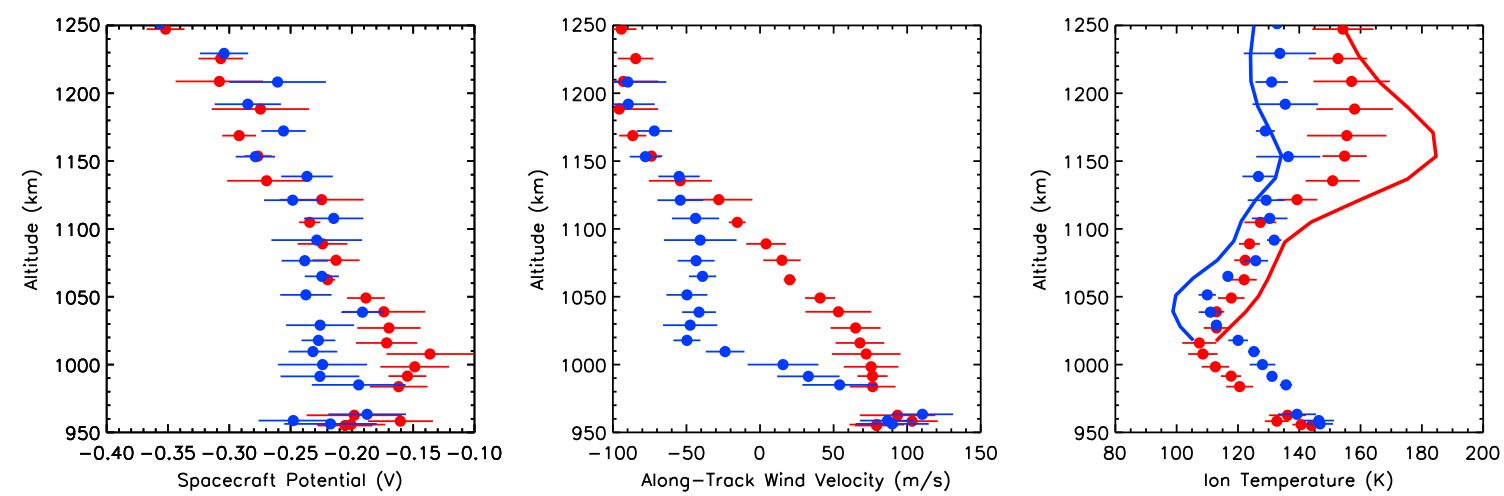

Figure 2. Shown are three panels which detail the results from the CAPS-IBS/INMS cross calibration for the T57 flyby with the inbound portion of the flyby in red and the outbound in blue. (left) The spacecraft potential, (middle) the along-track ion wind velocity, and (right) the ion temperature. The solid lines in the ion temperature panel are the INMS-derived neutral temperatures, which have errors of roughly $10 \mathrm{~K}$ in this region dependent on the upper boundary condition selected [Snowden et al., 2013]. There are two profiles per figure representing the inbound and outbound portions of the Cassini flyby. 
using several initial temperatures to determine if the fits were in any way affected by the initial choice. No evidence of influence of the initial temperature on the final fit parameters was found. To refine the spacecraft potential fit and obtain the along-track wind velocity, each peak grouping is fit independently. A peak group is selected by first locating the peaks and troughs in the data bounded by the INMS mass or energy range. This is accomplished by locating the zero crossings of the smoothed first derivative of the INMS flux spectrum. The peaks are then iteratively fit using the simplex method with the spacecraft potential, amplitude correction, and temperature as free parameters. The spacecraft potential obtained for this collection of mass peaks is mass dependent due to ion velocities along the direction of the motion of the spacecraft, also called along-track winds. The following linear model is used to determine the spacecraft potential and along-track wind

$$
\Phi_{\mathrm{Fit}}=\Phi_{\mathrm{SC}}+\frac{m w_{\mathrm{SC}} w_{\text {wind }}}{e}
$$

where $\Phi_{\text {Fit }}$ is the fit spacecraft potential, $w_{\mathrm{SC}}$ is the spacecraft velocity, and $w_{\text {wind }}$ is the along-track ambient ion velocity. The ion temperature for the spectra is determined by averaging the individual peak temperatures with the variance in the measurements being the standard deviation.

The mass grouping for the first carbon group is not energetic enough to be included in its entirety in the CAPS-IBS spectrum (the energy cutoff for CAPS-IBS is $3 \mathrm{eV}, \mathrm{CH}_{4}{ }^{+}$is expected at $2.45 \mathrm{eV}$ for a spacecraft velocity of $5.97 \mathrm{~km} / \mathrm{s}$ and a spacecraft potential of $-0.5 \mathrm{eV}$ ). Figure 2 shows the spacecraft potential, ion temperature, and along-track wind velocities of the T57 flyby used to produce the spectra and density profiles. We interpolate the values between the CAPS-IBS/INMS calibration points to determine the intermediate CAPS-IBS density values. We plot the INMS-derived neutral temperatures for the T57 flyby from Snowden et al. [2013]. Since the ions are chemical products of the neutrals, it is expected that the ions and neutrals would have similar temperature profiles. Differences in the ion and neutral temperatures would indicate a decoupling of these populations, which is not expected in a collisional regime. The observed correlation increases our confidence in the derived values.

The resultant densities for mass groups between the $\mathrm{C} 1$ and $\mathrm{C} 13$ are shown in Figure 3 . We also show the total electron density as observed by the Radio and Plasma Wave Science-Langmuir Probe (RPWS-LP) [Edberg et al., 2010] and the total ion densities for the INMS and CAPS-IBS observations. The densities observed in the CAPS-IBS and INMS have a mass-dependent sensitivity that was corrected for in these spectra. Crary et al. [2009] corrected this mass-dependent sensitivity using a linear correction factor applied to the CAPS-IBS data on a spectrum-by-spectrum basis. We find that a superior fit is obtained using a power law fit given by $n_{\text {group }}=24.0 N_{\text {Group }}{ }^{-1.9}$, where $n_{\text {group }}$ is the ion density of the group and $N_{\text {Group }}$ is the integer group number. This power law fit gives an $R^{2}$ value of 0.99 indicating a good fit, which can also be seen by the excellent correspondence between the INMS and CAPS-IBS altitude profiles. We posit that the mass-dependent sensitivity is tied to either an instrumental sensitivity in which higher-mass ions are not detected with the same efficiency as lower mass ions, or possibly detector cross talk. Both effects are the focus of currently ongoing studies within the CAPS team. Since we do not have INMS data past the C7 group, we extrapolate the power spectrum fit for ion densities into the higher-mass range of the CAPS-IBS.

\section{CAPS-IBS Data During the T57 Flyby}

For the T57 flyby it is possible to obtain detailed ionospheric density structure information due to the continuous sampling during the flyby. Previous Cassini flybys have actuated the CAPS instrument to obtaining various look directions throughout the flyby. Shown in Figure 3 are the total densities of the carbon groups C8-C13 versus altitude. The group density was obtained by integrating under the spectrum between the troughs in the spectrum. The interrelationship of the altitude structure of the various group densities holds clues to the processes controlling the production and loss of these ions. These ions show a region of initiation and density increase with decreasing altitude beginning at roughly $1100 \mathrm{~km}$ and stagnating near $1000 \mathrm{~km}$. The stagnation occurs roughly $125 \mathrm{~km}$ below the location of the peak ionization (see, for example, Lavvas et al. [2011a, 2011 b] and consistent with the electron density profile shown in Figure 3), which for T57 is located near $1125 \mathrm{~km}$. The decline in total ion density may be indicative of the overall level of primary electron ionization declining in the ionosphere. The lighter ion groups show a Chapman layer-like behavior with a peak density coincident with the peak photoionization rate, while the heavier ion groups 

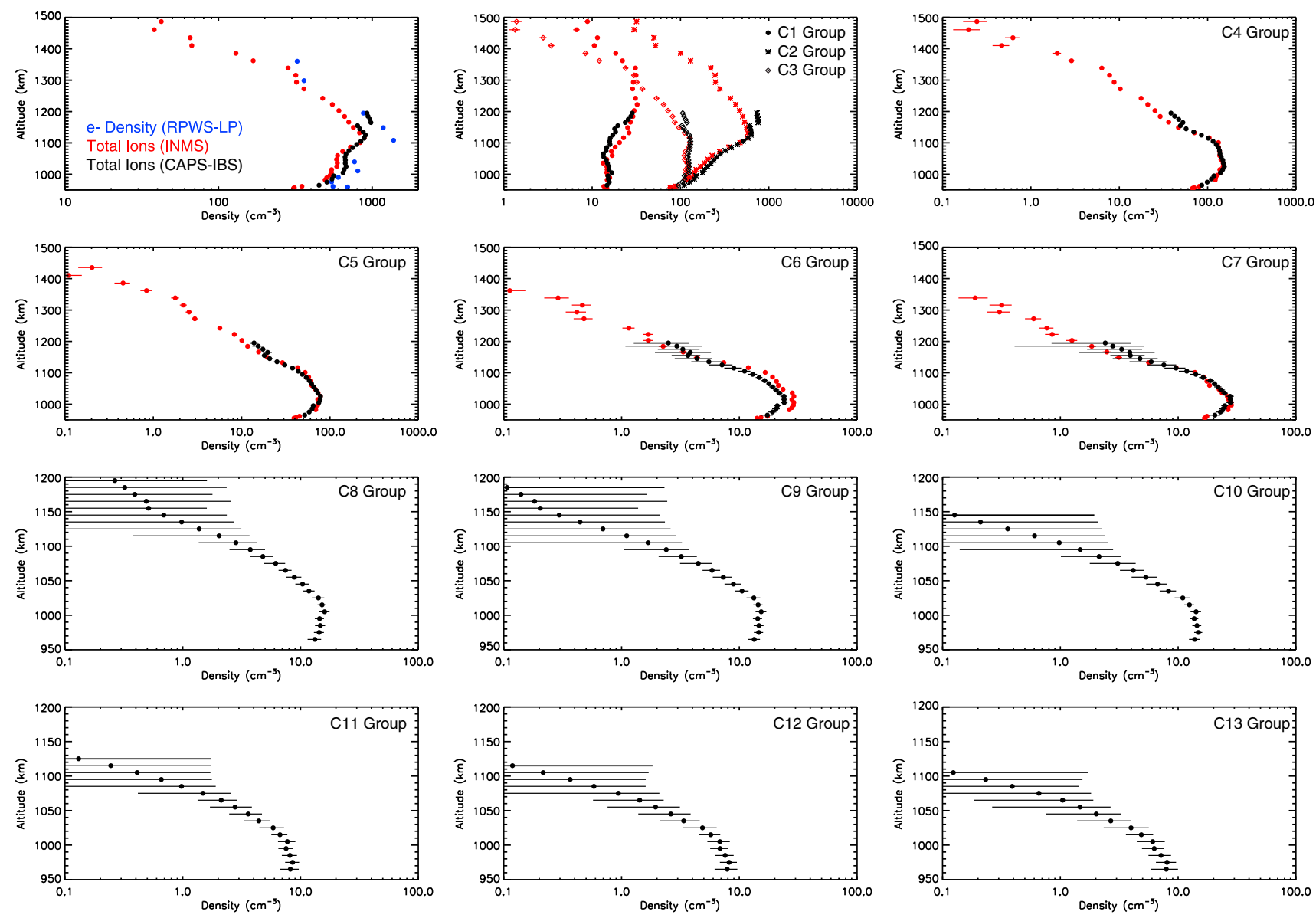

Figure 3. We present the group densities from the $\mathrm{C} 1$ to the $\mathrm{C} 13$ groups for the $\mathrm{T} 57$ flyby. A group density is simply the integrated density between the minima in the mass spectrum. The labeling using $C$ number indicates the number of heavy atoms (carbon, nitrogen, oxygen, etc.) expected within this mass grouping. The black points represent CAPS-IBS data, the red gives the INMS data, and the blue gives the RPWS-LP total electron density. The CAPS-IBS data are both summed within carbon groups and $10 \mathrm{~km}$ height bins. The error bars in the CAPS-IBS and INMS data represent the counting statistical counting errors.

appear to increase in density until about $1000 \mathrm{~km}$ where a stagnation in the density profiles is evident. This trend points to the peak production altitude falling with ion mass where the $\mathrm{C} 1-\mathrm{C} 3$ peak density occurs above $1100 \mathrm{~km}$, the C5-C7 peak is near $1000 \mathrm{~km}$, and the heavier ions possibly peaking at $960 \mathrm{~km}$ or lower.

The T57 density profiles are similar in structure to those presented for the T17 flyby by Vuitton et al. [2008]. These authors attribute the decline in observed densities compared to their model results at the lowest altitudes to incomplete coverage of the ion distribution function related to instrumental tuning issues or wind anomalies. Shown in Figure 4 are the density profiles of the total $\mathrm{C} 6$ group densities observed by the CAPS-IBS and INMS as well as the mass 77 and 79 signals observed by the INMS during the T57 flyby. If the decline in densities at the lowest altitudes were due to an instrumental mistuning of the INMS, then the CAPS-IBS measurements (both in cross-calibrated densities and in counting rates) should deviate from the INMS measurements. However, we find a very good correspondence in structure between the two profiles.

Furthermore, given the much wider acceptance angle of the CAPS-IBS, it is unlikely that winds are producing these falloffs in density. Lastly, there is a gap in the INMS data at the lowest altitudes where the quadrupole switching lens is scanned to verify the location of the measurement on the transmission curve shown in the inset of Figure 4. The INMS densities are corrected to the measured maximum transmission [Mandt et al., 2012]. This effect was observed but not yet corrected for during the T17 flyby by Vuitton et al. [2008], and we report this effect as being present for the T57 flyby as well. We note here that in assessing the entirety of the data from the T16 through T59 flybys, Westlake et al. [2012] report that this effect is present in nearly all flybys indicating that the dropoff in density at low altitudes cannot be attributed to a single flyby 


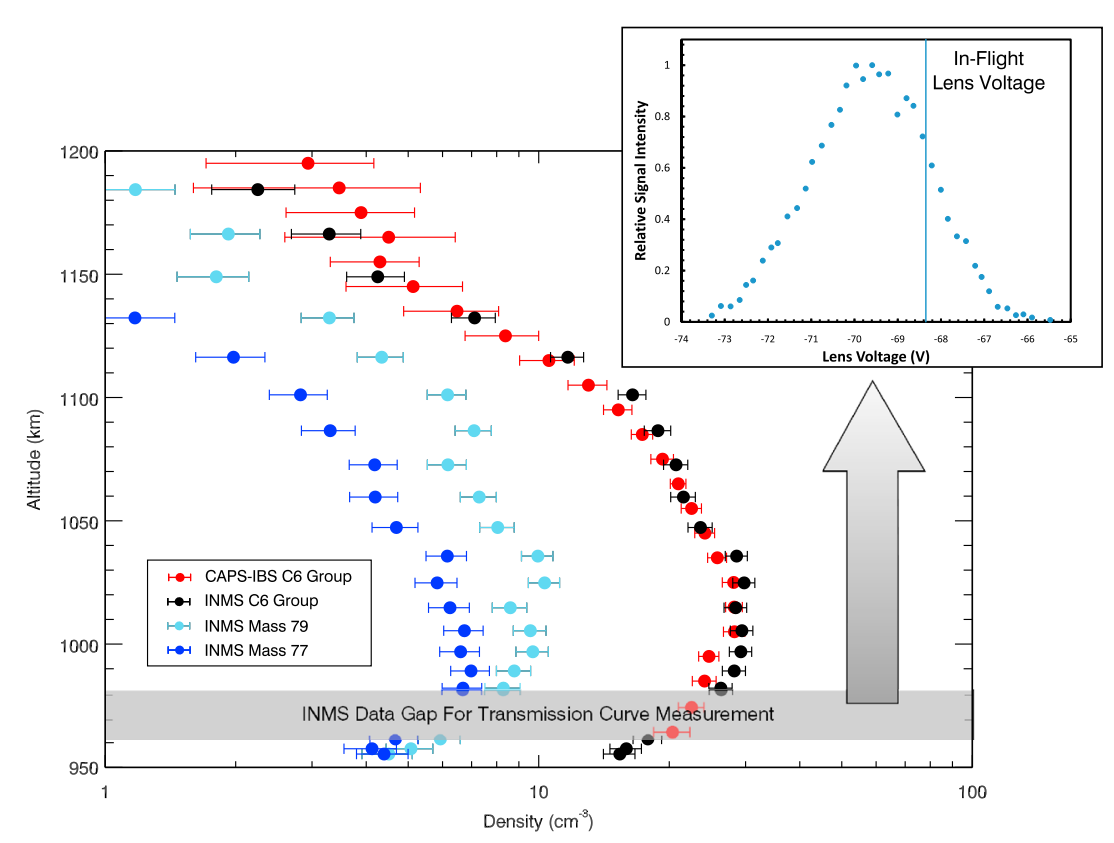

Figure 4. Densities of ions within the C6 group. Shown in red is the CAPS-IBS total group density and in black is the INMS total group density. In light blue are the INMS data from mass 79 which is attributed to $\mathrm{C}_{6} \mathrm{H}_{7}{ }^{+}$, and in blue are the mass 77 data which are attributed to $\mathrm{C}_{6} \mathrm{H}_{5}{ }^{+}$. The inset figure shows the INMS instrument tuning scan taken during the data gap near $975 \mathrm{~km}$. This procedure scans the instrument ion transmission lens to determine whether the velocity filter is set appropriately. The vertical line shows the lens voltage setting used during this flyby; the INMS densities are then corrected to this peak value.

anomaly such as a cross-track wind or spacecraft potential. Therefore, we confirm through the CAPS-IBS data that the ion densities drop off below $1000 \mathrm{~km}$ consistent with the electron density, as previously observed in the INMS data [Westlake et al., 2012].

\section{High-Mass Ion Structure and Growth}

The density profile of each ion is dependent upon the production, loss, and transport processes acting on the ions. Ion production results from photoionization, electron-impact ionization, or ion-neutral chemistry. In this study we will separate each of these production processes and assess their viability as the process responsible for the production of the high-mass ions. Because we do not have accurate assessments of the composition due to the low-mass resolution of the CAPS-IBS and little experimental data exists for these large ions, we must make several educated assumptions about these processes. In this study we compare the following hypotheses: (1) they are produced via electron-impact ionization of ambient neutrals; (2) they are produced via proton exchange reactions of ambient neutrals with $\mathrm{CH}_{5}{ }^{+}, \mathrm{C}_{2} \mathrm{H}_{5}{ }^{+}$, and $\mathrm{HCNH}^{+}$; and (3) they are produced via ion-molecule growth processes utilizing suitable hydrocarbon building blocks such as $\mathrm{C}_{2} \mathrm{H}_{2}$ and $\mathrm{C}_{2} \mathrm{H}_{4}$. For each of these possibilities we assume that the primary loss of ions is through electron recombination and that transport plays a negligible role. We then discuss the implications for each possibility on the relevant observables from Cassini.

For each case presented below we assume photochemical equilibrium since the chemical lifetimes are significantly shorter than the dynamical lifetimes [Cravens et al., 2009; Ma et al., 2006]. For photochemical equilibrium the continuity equation is given by the following formula:

$$
\frac{\mathrm{d} n_{i}}{\mathrm{~d} t}+\nabla \cdot\left(n_{i} u_{i}\right)=P_{i}-L_{i} n_{i}
$$

where $n_{i}$ is the density, $P_{i}$ is the production rate, and $L_{i}$ is the loss rate, all for the ion species $i$. We utilize the INMS-derived neutral densities for the T57 flyby [Westlake et al., 2011]. For the photochemical 
equilibrium assumption we set $\mathrm{d} n_{i} / \mathrm{d} t$ equal to zero. In each case we include electron recombination defined by the equation

$$
L_{i}^{\mathrm{ER}}=\alpha_{i}\left(\frac{300}{T_{e}}\right)^{\beta_{i}} n_{e}
$$

where $\alpha_{i}$ and $\beta_{i}$ are parameters determined in the laboratory, $T_{e}$ is the electron temperature, and $n_{e}$ is the electron density. In the absence of laboratory data, we assume an $\alpha_{i}$ of $1.0 \times 10^{-6} \mathrm{~cm}^{3} \mathrm{~s}^{-1}$ and a $\beta_{i}$ of 0.7 for the high-mass ions, which is similar to the measured recombination rate for $\mathrm{C}_{6} \mathrm{H}_{6}{ }^{+}$and $\mathrm{C}_{8} \mathrm{H}_{7}{ }^{+}$[e.g., Abouelaziz et al., 1993; Rebrion-Rowe et al., 1998].

Additional losses of the high-mass ions could come from ion-ion recombination of negative ions with these ions. A common formulation for this rate coefficient is that developed by Hickman [1979] that utilizes a complex potential model of the mutual neutralization reaction given by

$$
k=5.34 \times 10^{-7} E A^{-0.4} m_{i j}^{-0.5}\left(\frac{T_{\text {gas }}}{300}\right)^{-0.5} \mathrm{~cm}^{3} \mathrm{~s}^{-1}
$$

Rate coefficients for this process range from about $5 \times 10^{-8} \mathrm{~cm}^{3} \mathrm{~s}^{-1}$ to $1 \times 10^{-7} \mathrm{~cm}^{3} \mathrm{~s}^{-1}$. Therefore, for a negative ion density of about $1000 \mathrm{~cm}^{3}$ [Wellbrock et al., 2013] we retrieve a loss rate of about $5 \times 10^{-5} \mathrm{~s}^{-1}$ to $1 \times 10^{-6} \mathrm{~s}^{-1}$, which is very small compared to the electron recombination loss rate of about $10^{3} \mathrm{~s}^{-1}$ for this flyby. We therefore neglect this process in our calculations.

\subsection{Case 1: Direct lonization of Ambient Neutrals}

We calculate the production of high-mass ions from the electron-impact ionization process using the twostream calculations of M. S. Richard et al. (An empirical approach to modeling ion production rates in Titan's ionosphere II: Ion production rates on the nightside, submitted to Journal of Geophysical Research, 2014) for the nightside electron fluxes. Since we do not know the chemical composition of these ions, we can only suggest an analog for their electron-impact ionization behavior. We utilize the electron-impact ionization cross sections for benzene $\left(\mathrm{C}_{6} \mathrm{H}_{6}\right)$ for this, which assumes that the heavier neutrals would have a similar cross section and that the composition of the large neutrals is represented by an aromatic hydrocarbon. Benzene has a relatively large cross section for electron-impact ionization (a peak of $1.5 \times 10^{-15} \mathrm{~cm}^{2}$ near $75 \mathrm{eV}$ compared to say acetylene which has a peak cross section of $5 \times 10^{-16} \mathrm{~cm}^{2}$ ), so this can be considered a best case scenario for the production of heavy ions through electron-impact ionization. The benzene cross sections are given from the National Institute of Standards and Technology database for electron-impact ionization and excitation, which are calculated using the Binary-Encounter-Bethe model. We assume that the only loss comes from electron recombination with a coefficient of $\alpha=1.0 \times 10^{-6} \times\left(300 / T_{e}\right)^{0.7}$.

We show the resulting neutral densities required to produce the high-mass ions purely through electronimpact ionization in Figure 5. We find that for this case the neutral densities required to produce the observed high-mass ions are several orders of magnitude greater than any observed minor atmospheric constituent at Titan. It is clear that electron-impact ionization of the high-mass neutrals is an inefficient process and is not likely to contribute significantly to the high-mass ions observed. We note that it is likely that the higher-mass neutrals will have a larger cross section than benzene for electron-impact ionization; however, the cross sections are not expected to be several orders of magnitude larger than benzene, which is required to yield production rates sufficient to yield the required neutral densities.

An alternative hypothesis is that the ions were produced through photoionization on the dayside or the flanks and transported to the nightside. The studies of Cui et al. [2009b, 2010] have proposed that the long lifetime of the complex hydrocarbon ions in Titan's ionosphere and horizontal motion of the ions could lead to substantial densities of these ions on the nightside and would appear as density enhancements with respect to the primary ionization products on the nightside. We note that in order for transport to provide substantial densities of long-lived ions on Titan's nightside without a primary ionization source requires large horizontal ion velocities that would result in breakdown of the assumption of photochemical equilibrium, an assumption that has proven valid for several models (e.g., Cravens et al. [2006], De La Haye et al. [2008], 


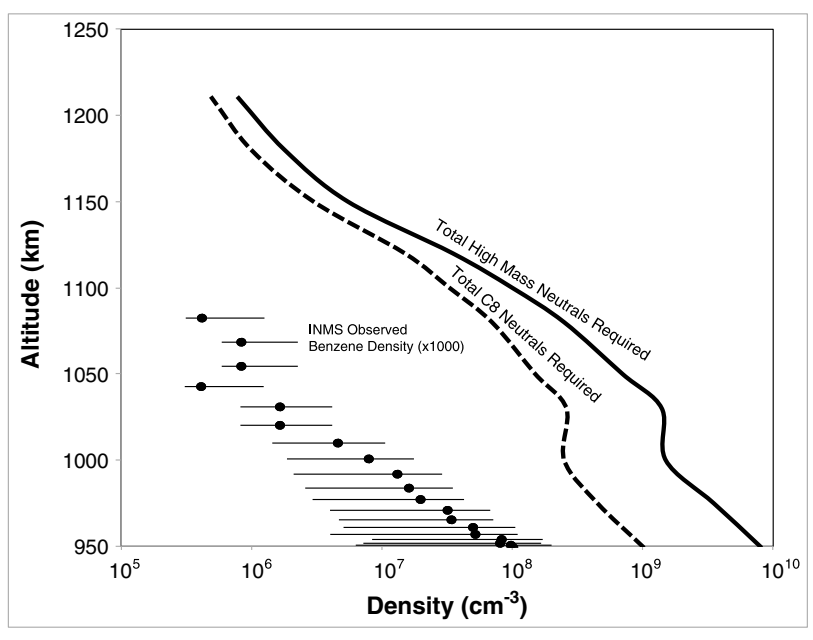

Figure 5. Shown are the calculated neutral density profiles required to produce the ions observed for the $\mathrm{C} 8-\mathrm{C} 13$ groups using only electronimpact ionization processes. The dashed line shows one example profile for the C8 group, and the solid line gives the total C8-C13 neutrals required to produce the high-mass ion signal solely through electronimpact ionization. For comparison we also show the INMS-observed benzene density multiplied by 1000 from Waite et al. [2007].

Westlake et al. [2012], and MHD comparisons with photochemical model assumptions in Ma et al. [2006]). Additionally, the neutral wind velocities produced by global circulation models have not indicated that winds of this magnitude are present in Titan's ionosphere [Bell et al., 2010]

\subsection{Case 2: Proton Exchange of $\mathrm{CH}_{5}{ }^{+}$ $\mathrm{C}_{2} \mathrm{H}_{5}{ }^{+}$, and $\mathrm{HCNH}^{+}$With Ambient Neutrals}

If we consider that the ions are produced through proton exchange with the major ions, we can derive a relation that gives the required large neutral density for this model. To do this we solve equation (5) assuming that the ion production comes solely from three ion-molecule reactions (one for each of the major ions) at a fixed, roughly collisional rate coefficient of $1 \times 10^{-9} \mathrm{~cm}^{-3} \mathrm{~s}^{-1}$. This gives the following relation:

$$
k_{p} n_{\text {neutral }} n_{\mathrm{CH}_{5}^{+}}+k_{p} n_{\text {neutral }} n_{\mathrm{C}_{2} \mathrm{H}_{5}^{+}}+k_{p} n_{\text {neutral }} n_{\mathrm{HCNH}^{+}}=n_{\text {ion }} \alpha N_{e}
$$

which we solve for $n_{\text {neutral }}$ giving the required neutral density to produce the observed ion density. We calculate this value for two cases, the minimum density case that utilizes both the collisional reaction rate and the

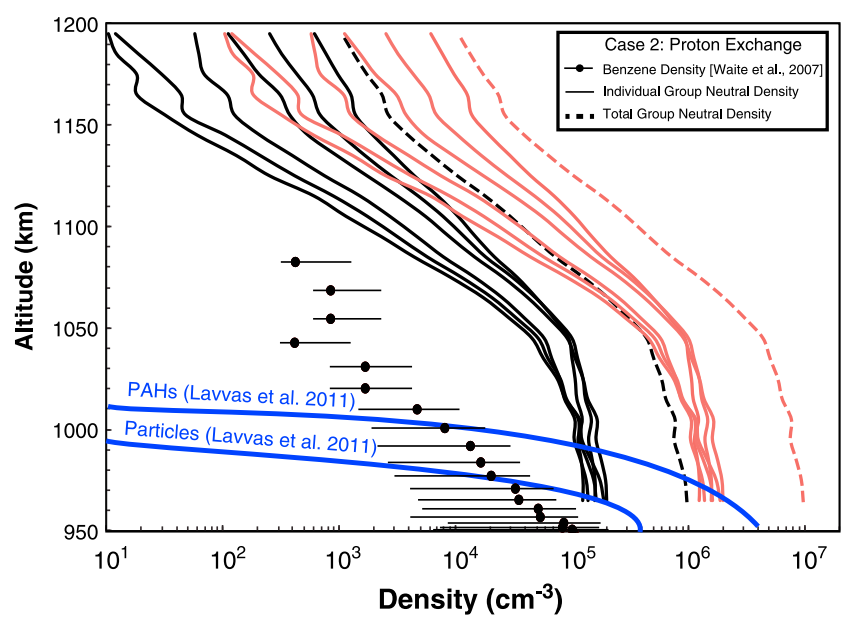

Figure 6. Shown are the calculated neutral density profiles required to produce the ions observed in the $\mathrm{C} 8-\mathrm{C} 13$ groups using only proton exchange of $\mathrm{CH}_{5}{ }^{+}, \mathrm{C}_{2} \mathrm{H}_{5}{ }^{+}$, and $\mathrm{HCNH}^{+}$with ambient high-mass neutrals. The solid lines give the total high-mass neutral density required for each group, and the dashed line gives the total for the C8-C11 groups combined. The black curves show the minimum density case for an efficient proton exchange reaction, while the red curves show the maximum density for a less efficient reaction rate. Plotted for comparison are the benzene densities observed by the INMS instrument [Waite et al., 2007] and the quantity of polycyclic aromatic hydrocarbons or PAHs and larger aerosol particles derived from the Lavvas et al. [2011a, 2011b] aerosol growth model. electron recombination rate coefficient of $\alpha=1.0 \times 10^{-6 *}\left(300 / T_{e}\right)^{0.7}$; for the maximum density case we consider a less efficient reaction rate of $1 \times 10^{-10} \mathrm{~cm}^{-3} \mathrm{~s}^{-1}$. The resulting neutral density profiles required to produce these large ions in this case are shown in Figure 6. The minimum densities required are larger than the INMS-measured density of benzene.

We compare the required neutral densities with the aerosol production model of Lavvas et al. [2011a, 2011b]. This model follows a stochastic approach building from the thermospheric benzene to produce polycyclic aromatic hydrocarbons (PAHs) and particles (aerosols). The densities of large neutrals predicted from this model are insufficient to produce these ions through proton exchange reactions. We are therefore compelled to reject this hypothesis as being the sole process responsible for producing the large ions. We further note that the scale height of these neutrals would be expected to be 
Table 1. The Reactions Producing and Consuming $\mathrm{C} 8$ and Larger lons

\begin{tabular}{|c|c|c|c|}
\hline Reaction Number & Reaction & $k\left(\mathrm{~cm}^{3} \mathrm{~s}^{-1}\right)$ & Reference \\
\hline$k_{1}$ & $\mathrm{C}_{5} \mathrm{H}_{7}^{+}+\mathrm{CH}_{3} \mathrm{C}_{2} \mathrm{H} \rightarrow \mathrm{C}_{8} \mathrm{H}_{11}^{+}$ & $7.0 \times 10^{-10}$ & Anicich et al. [2006] \\
\hline$k_{2}$ & $\mathrm{C}_{6} \mathrm{H}_{3}^{+}+\mathrm{C}_{2} \mathrm{H}_{2} \rightarrow \mathrm{C}_{8} \mathrm{H}_{5}^{+}+\mathrm{H}$ & $2.3 \times 10^{-10}$ & Anicich et al. [2006] \\
\hline$k_{3}$ & $\mathrm{C}_{6} \mathrm{H}_{4}^{+}+\mathrm{C}_{2} \mathrm{H}_{2} \rightarrow \mathrm{C}_{8} \mathrm{H}_{6}^{+}+\mathrm{H}$ & $2.9 \times 10^{-10}$ & Anicich et al. [2006] \\
\hline$k_{4}$ & $\mathrm{C}_{6} \mathrm{H}_{5}^{+}+\mathrm{C}_{2} \mathrm{H}_{2} \rightarrow \mathrm{C}_{8} \mathrm{H}_{7}^{+}+\mathrm{hv}$ & $1.7 \times 10^{-10}$ & Anicich et al. [2006] \\
\hline$k_{5}$ & $\mathrm{C}_{6} \mathrm{H}_{5}^{+}+\mathrm{C}_{2} \mathrm{H}_{4} \rightarrow \mathrm{C}_{8} \mathrm{H}_{7}^{+}+\mathrm{H}_{2}$ & $4.8 \times 10^{-11}$ & Anicich et al. [2006] \\
\hline$k_{6}$ & $\mathrm{C}_{3} \mathrm{H}_{5}^{+}+\mathrm{C}_{7} \mathrm{H}_{8} \rightarrow \mathrm{C}_{8} \mathrm{H}_{9}^{+}+\mathrm{C}_{2} \mathrm{H}_{4}$ & $1.0 \times 10^{-9}$ & Houriet et al. [1978] \\
\hline$k_{7}$ & $\mathrm{C}_{5} \mathrm{H}_{2}^{+}+\mathrm{C}_{3} \mathrm{H}_{4} \rightarrow \mathrm{C}_{8} \mathrm{H}_{4}^{+}+\mathrm{H}_{2}$ & $8.7 \times 10^{-10}$ & OSU $^{a}$ \\
\hline$k_{8}$ & $\mathrm{C}_{6} \mathrm{H}_{2}^{+}+\mathrm{C}_{2} \mathrm{H}_{4} \rightarrow \mathrm{C}_{8} \mathrm{H}_{7}^{+}+\mathrm{H}_{2}$ & $1.0 \times 10^{-9}$ & McElroy et al. [2013] \\
\hline$k_{9}$ & $\mathrm{C}_{6} \mathrm{H}_{3}{ }^{+}+\mathrm{C}_{2} \mathrm{H}_{2} \rightarrow \mathrm{C}_{8} \mathrm{H}_{5}^{+}+\mathrm{hv}$ & $2.3 \times 10^{-10}$ & Anicich et al. [2006] \\
\hline$k_{10}$ & $\mathrm{C}_{6} \mathrm{H}_{4}^{+}+\mathrm{C}_{2} \mathrm{H}_{2} \rightarrow \mathrm{C}_{8} \mathrm{H}_{6}^{+}+\mathrm{hv}$ & $2.9 \times 10^{-10}$ & Anicich et al. [2006] \\
\hline$k_{11}$ & $\mathrm{C}_{7} \mathrm{H}_{2}^{+}+\mathrm{CH}_{4} \rightarrow \mathrm{C}_{8} \mathrm{H}_{4}^{+}+\mathrm{H}_{2}$ & $1.0 \times 10^{-9}$ & OSU \\
\hline$k_{12}$ & $\mathrm{C}_{7} \mathrm{H}_{7}^{+}+\mathrm{C}_{7} \mathrm{H}_{8} \rightarrow \mathrm{C}_{8} \mathrm{H}_{9}^{+}+\mathrm{C}_{6} \mathrm{H}_{6}$ & $1.6 \times 10^{-10}$ & Bartmess [1982] \\
\hline$k_{13}$ & $\mathrm{I}_{-} \mathrm{C}_{3} \mathrm{H}_{3}{ }^{+}+\mathrm{C}_{6} \mathrm{H}_{6} \rightarrow \mathrm{C}_{9} \mathrm{H}_{7}^{+}$ & $7.0 \times 10^{-10}$ & Smyth et al. [1982] \\
\hline$k_{14}$ & $\mathrm{C}_{5} \mathrm{H}_{5}^{+}+\mathrm{C}_{4} \mathrm{H}_{2} \rightarrow \mathrm{C}_{9} \mathrm{H}_{7}^{+}$ & $2.2 \times 10^{-10}$ & Ozturk et al. [1989] \\
\hline$k_{15}$ & $\mathrm{C}_{6} \mathrm{H}_{5}^{+}+\mathrm{CH}_{3} \mathrm{C}_{2} \mathrm{H} \rightarrow \mathrm{C}_{9} \mathrm{H}_{7}^{+}+\mathrm{H}_{2}$ & $1.8 \times 10^{-10}$ & Anicich [2003] \\
\hline$k_{16}$ & $\mathrm{C}_{6} \mathrm{H}_{5}^{+}+\mathrm{CH}_{3} \mathrm{C}_{2} \mathrm{H} \rightarrow \mathrm{C}_{9} \mathrm{H}_{8}^{+}+\mathrm{H}$ & $1.2 \times 10^{-11}$ & Anicich [2003] \\
\hline$k_{17}$ & $\mathrm{C}_{7} \mathrm{H}_{7}^{+}+\mathrm{C}_{2} \mathrm{H}_{4} \rightarrow \mathrm{C}_{9} \mathrm{H}_{11}^{+}$ & $2.0 \times 10^{-10}$ & Anicich et al. [2006] \\
\hline$k_{18}$ & $\mathrm{C}_{6} \mathrm{H}_{4}^{+}+\mathrm{C}_{6} \mathrm{H}_{6} \rightarrow \mathrm{C}_{12} \mathrm{H}_{8}^{+}+\mathrm{H}_{2}$ & $1.0 \times 10^{-9}$ & Anicich et al. [2006] \\
\hline$k_{19}$ & $\mathrm{C}_{9} \mathrm{H}_{7}^{+}+\mathrm{CH}_{3} \mathrm{C}_{2} \mathrm{H} \rightarrow \mathrm{C}_{12} \mathrm{H}_{11}{ }^{+}$ & $2.8 \times 10^{-9}$ & Anicich et al. [2006] \\
\hline
\end{tabular}

${ }^{a}$ OSU, Ohio State University database (http://www.physics.ohio-state.edu/ eric/research.html, version osu_01_2009).

smaller than that of benzene given their larger mass; however, the derived profiles show a larger scale height than benzene.

\subsection{Case 3: Ion-Molecule Reactions}

We propose that an alternate hypothesis by utilizing abundant hydrocarbon building blocks such as acetylene, ethylene, and hydrogen cyanide can reproduce the implied altitude-dependent growth rates through ion-molecule reactions. We suggest this process because it has been shown to be efficient in the lighter ions [Carrasco et al. 2008; Westlake et al., 2012], and recent calculations have shown that this process is energetically favorable [Ghesquière et al., 2014]. This ion-molecule building of multiringed PAHs has also been suggested to be present in various flame chemistries [e.g., Calcote, 1981]. To test this hypothesis we solve the continuity equation for the $\mathrm{C} 8$ and heavier ions assuming photochemical equilibrium as was done for the previous two cases. We utilize only known reactions, listed in Table 1, to produce the C8 and C9 species, and we also include the known reactions for the production of $\mathrm{C} 12$ ions. We then insert a chemical scheme that utilizes acetylene and ethylene as building blocks for producing and consuming the ion species within the group. Our analysis leads us to suggest the following general chemical scheme to address the large molecular ion chemistry.

$$
\begin{gathered}
\mathrm{C}_{x} \mathrm{H}_{y}^{+}+\mathrm{C}_{2} \mathrm{H}_{2} \rightarrow \mathrm{C}_{x+2} \mathrm{H}_{y+1}^{+}+\mathrm{H} \\
\mathrm{C}_{x} \mathrm{H}_{y}^{+}+\mathrm{C}_{2} \mathrm{H}_{2} \rightarrow \mathrm{C}_{x+2} \mathrm{H}_{y+2}^{+} \\
\mathrm{C}_{x} \mathrm{H}_{y}^{+}+\mathrm{C}_{2} \mathrm{H}_{4} \rightarrow \mathrm{C}_{x+2} \mathrm{H}_{y+2}^{+}+\mathrm{H}_{2}
\end{gathered}
$$

A recent study by Ghesquière et al. [2014] showed that the reactions of the benzene cation with acetylene produce a fused ring PAHs such as naphthalene and that this reaction is energetically favorable. Additionally, the calculations of Vuitton et al. [2012] have shown that radiative association reactions could be an important source of these large ions as well (e.g., reaction $k_{4}$ in Table 1). In the absence of laboratory data we assume that these processes proceed with a rate coefficient equal to or less than the measured reaction of $\mathrm{C}_{6} \mathrm{H}_{5}{ }^{+}$with methane, acetylene, and ethylene. We model the high-mass ion densities using three fixed ion-molecule reaction rate coefficients between the high-mass ions and $\mathrm{C}_{2} \mathrm{H}_{2}$ and $\mathrm{C}_{2} \mathrm{H}_{4}\left(1 \times 10^{-11}, 5 \times 10^{-11}\right.$, and $\left.1 \times 10^{-10} \mathrm{~cm}^{3} \mathrm{~s}^{-1}\right)$. We note that it is possible that nitrogen is incorporated into the high-mass ions with 

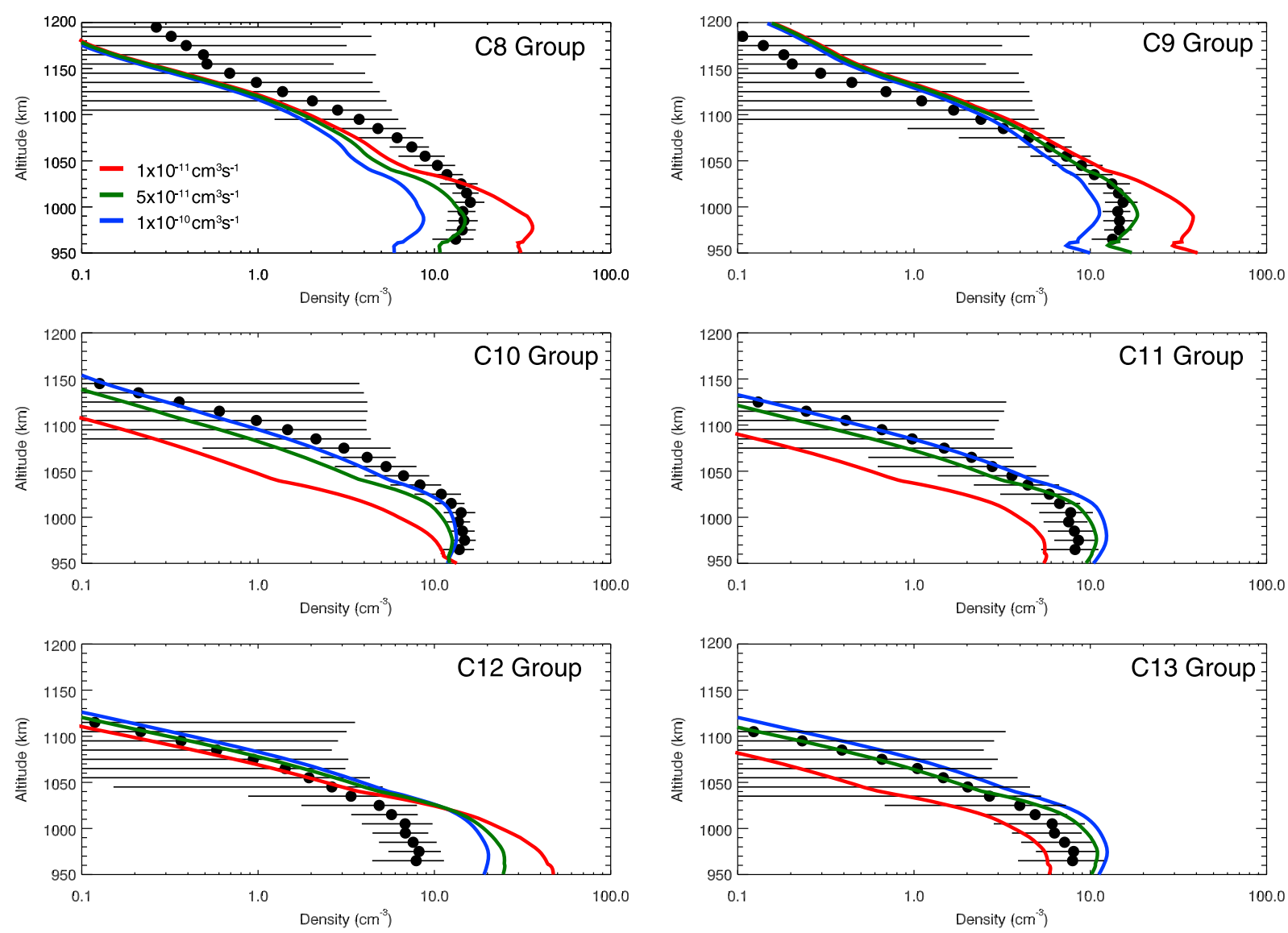

Figure 7. Shown are the results of the study on the $\mathrm{C} 8$ through the $\mathrm{C} 13$ group ions. The points are the summed CAPS-IBS group densities from the T57 flyby while the solid line shows the modeled ion profiles. We show three cases of fixed reaction rate coefficients ranging from $1 \times 10^{-11} \mathrm{~cm}^{3} \mathrm{~s}^{-1}$ to $1 \times 10^{-10} \mathrm{~cm}^{3} \mathrm{~s}^{-1}$.

HCN substituted for acetylene and ethylene in our suggested chemical process [e.g., Ricca et al., 2001]. This is understandably an oversimplification of the processes producing these ions; however, it demonstrates that the reservoir of hydrocarbon building blocks such as acetylene and ethylene are a sufficient resource

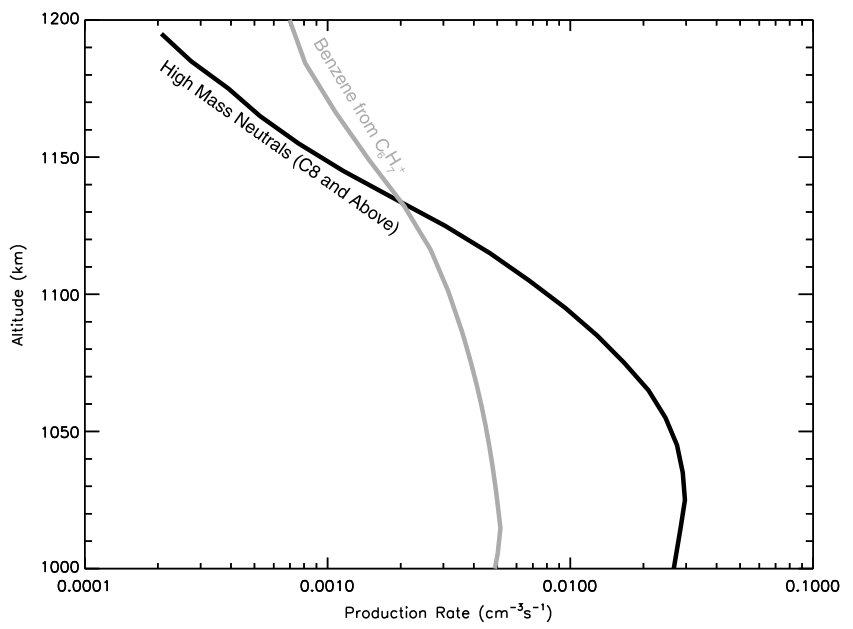

Figure 8. The implied production rate of large molecules in Titan's ionosphere through electron recombination of the ions with masses greater than 100 amu. For comparison the production of benzene through electron recombination of $\mathrm{C}_{6} \mathrm{H}_{7}{ }^{+}$is shown. for the building of the observed highmass ions.

Shown in Figure 7 are the high-mass ion model results utilizing three fixed rate coefficients for the proposed reactions, $1 \times 10^{-11} \mathrm{~cm}^{3} \mathrm{~s}^{-1}, 5 \times 10^{-11} \mathrm{~cm}^{3} \mathrm{~s}^{-1}$, and $1 \times 10^{-10} \mathrm{~cm}^{3} \mathrm{~s}^{-1}$. These rate coefficients are all below the collisional rate and would represent an average rate coefficient of the ion species with $\mathrm{C}_{2} \mathrm{H}_{2}$ and $\mathrm{C}_{2} \mathrm{H}_{4}$. Since these reactions have not been measured in the laboratory, we imply that these processes are plausible to produce the high-mass ions with reasonable reaction rates. We note that the $\mathrm{C} 12$ and $\mathrm{C} 13$ loss rates are elevated from their predecessor ions; this is because we have not extended the chemistry past the C13 group, and thus, this loss 
rate has the additional loss rates of the ions that are larger contained within it. The calculated density profiles show good correspondence to the measured profiles over the entire altitude range indicating that the skeletal processes are implemented with the correct neutrals and are of the magnitude required to match the data.

From the production and loss calculations performed above it is possible to calculate the implied high-mass neutral molecule production rate from electron recombination. For the large ions we assume a recombination rate with an $\alpha$ value of $1.0 \times 10^{-6}$ and a $\beta$ value of 0.7 . Shown in Figure 8 is the production rate of large molecular neutrals implied from the density of ions and the recombination rate coefficients. This production rate is comparable to that of benzene from the dissociative recombination of $\mathrm{C}_{6} \mathrm{H}_{7}{ }^{+}$, shown in the grey profiles in Figure 8, and is likely to produce substantial amounts of large molecules. Integrating under the curves allows us to derive a production rate for benzene from electron recombination of $\mathrm{C}_{6} \mathrm{H}_{7}^{+}$of $2.4 \times 10^{-16} \mathrm{~g} \mathrm{~cm}^{-2} \mathrm{~s}^{-1}$ and a production rate for large molecules of $7.1 \times 10^{-16} \mathrm{~g} \mathrm{~cm}^{-2} \mathrm{~s}^{-1}$.

\section{Conclusions}

Both the Cassini INMS and CAPS-IBS instruments reveal immense chemical complexity in ion structure during the nightside T57 flyby. Peaks are identifiable in the CAPS-IBS spectra up to the C13 group. The use of the CAPS-IBS instrument as a rudimentary mass spectrometer has yielded enhanced scientific return beyond the mass range of the INMS. Furthermore, the cross calibration of the CAPS-IBS with the INMS has produced secondary results such as the spacecraft potential, cross-calibration factor, and along-track ion wind velocities that can be further compared to data obtained by the Langmuir probe on Cassini and used for modeling efforts of Titan.

The density profiles of the large ions in Titan's atmosphere were presented for the C6-C13 ions. With special attention paid to the high time-resolution measurements of the T57 flyby, we found that the ion density profiles show a region of initiation and growth followed by a stagnation region below about $1000 \mathrm{~km}$. We attribute this turnover not to instrumental effects but to the decreasing ionization in the upper atmosphere. Furthermore, within these altitude profiles lie clues as to the processes are responsible for the production and loss of these ions.

We test three hypotheses for the production of the large ions: (1) production via electron-impact ionization of ambient neutrals; (2) production via proton exchange reactions of ambient neutrals with $\mathrm{CH}_{5}{ }^{+}, \mathrm{C}_{2} \mathrm{H}_{5}{ }^{+}$, and $\mathrm{HCNH}^{+}$; and (3) production via ion-molecule growth processes utilizing suitable hydrocarbon building blocks such as $\mathrm{C}_{2} \mathrm{H}_{2}$ and $\mathrm{C}_{2} \mathrm{H}_{4}$. The neutral densities required to satisfy hypotheses (1) and (2) are found to be large in comparison to observed large molecule densities measured by INMS given the quantities expected from models and from the effectiveness of termolecular reaction processes in the upper atmosphere to produce large molecules. Ion-molecule reaction processes are therefore the most likely process as they are energetically favorable, utilize observed and abundant molecular building blocks, and do not require large quantities of ambient high-mass neutrals.

From the observed ion densities and an assumed electron recombination rate, we derive a production rate for the large neutrals and benzene. We derive a production rate for benzene from electron recombination of $\mathrm{C}_{6} \mathrm{H}_{7}{ }^{+}$of $2.4 \times 10^{-16} \mathrm{~g} \mathrm{~cm}^{-2} \mathrm{~s}^{-1}$ and a production rate for large hydrocarbon molecules of $7.1 \times 10^{-16} \mathrm{~g} \mathrm{~cm}^{-2} \mathrm{~s}^{-1}$. The rate for the production of benzene is larger than but comparable to the production rate derived by Vuitton et al. [2008] of $10^{-15} \mathrm{~g} \mathrm{~cm}^{-2} \mathrm{~s}^{-1}$. Waite et al. [2007] estimated a production rate for large neutral molecules of $10^{-16} \mathrm{~g} \mathrm{~cm}^{-2} \mathrm{~s}^{-1}$ from benzene. Their assumption was that the condensation of the large molecules was one tenth that of chemical processes. We note that the production rate of the large molecules contributes a substantial source population of large molecules for the middle and lower atmosphere and surface of Titan.

This work highlights the need for laboratory measurements of the reactions of large hydrocarbon and nitrogen containing hydrocarbon ions in environments representative of Titan's ionosphere. The discovery of currently unidentified reaction pathways and the reactions of ions that have not been extensively studied such as those in the C8-C13 groups are required to further analyze the wealth of compositional information returned by the Cassini observations. Furthermore, systematic studies of the deviation of the minor neutral and ion composition observed by the INMS would add to the accuracy of such modeling as it will remove several free parameters such as the densities of $\mathrm{CH}_{4}, \mathrm{HCN}, \mathrm{C}_{2} \mathrm{H}_{2}$, and $\mathrm{C}_{2} \mathrm{H}_{4}$. 


\section{Acknowledgments}

This work was supported by NASA Headquarters under the NASA Earth and Space Science Fellowship Program grant "NNX08AW24H" and support from the Cassini INMS instrument. N.C. thanks the ANR-09-JCJC-0038 contract for its financial support. The Cassini INMS CAPS, and RPWS data utilized in this paper are available through the PDS.

Michael Liemohn thanks the reviewers for their assistance in evaluating this paper.

\section{References}

Abouelaziz, H., J. C. Gomet, D. Pasquerault, B. R. Rowe, and J. B. A. Mitchell (1993), Measurements of C3H3+, C5H3+, C6H6+, C7H5+, and $\mathrm{C} 10 \mathrm{H} 8+$ dissociative recombination rate coefficients, J. Chem. Phys., 99, 237-243.

Anicich, V. G. (2003), An index of the literature for bimolecular gas phase cation-molecule reaction kinetics, JPL Publication 03-19, Jet Propulsion Lab., Calif. Inst. of Tech., Pasadena, Calif.

Anicich, V. G., P. F. Wilson, and M. J. McEwan (2006), An ICR study of ion-molecules reactions relevant to Titan's atmosphere: An investigation of binary hydrocarbon mixtures up to 1 micron, J. Am. Soc. Mass Spectrom., 17(4), 544-61, doi:10.1016/j.jasms.2005.11.022.

Bartmess, J. E. (1982), Gas-phase ion chemistry of 5-methylene-1, 3-cyclohexadiene (o-isotoluene) and 3-methylene-1, 4-cyclohexadiene (p-isotoluene), J. Am. Chem. Soc., 104(1), 335-337, doi:10.1021/ja00365a082.

Bell, J. M., et al. (2010), Simulating the one-dimensional structure of Titan's upper atmosphere: 1. Formulation of the Titan Global lonosphereThermosphere Model and benchmark simulations, J. Geophys. Res., 115, E12002, doi:10.1029/2010JE003636.

Calcote, H. F. (1981), Mechanisms of soot nucleation in flames-A critical review, Combust. Flame, 42, 215-242.

Carrasco, N., C. Alcaraz, O. Dutuit, S. Plessis, R. Thissen, V. Vuitton, R. Yelle, and P. Pernot (2008), Sensitivity of a Titan ionospheric model to the ion-molecule reaction parameters, Planet. Space Sci., 56(12), 1644-1657, doi:10.1016/j.pss.2008.04.007.

Coates, A. J., F. J. Crary, G. R. Lewis, D. T. Young, J. H. Waite, and E. C. Sittler (2007), Discovery of heavy negative ions in Titan's ionosphere, Geophys. Res. Lett., 34, L22103, doi:10.1029/2007GL030978.

Crary, F. J., B. A. Magee, K. Mandt, J. H. Waite Jr., J. Westlake, and D. T. Young (2009), Heavy ions, temperatures and winds in Titan's ionosphere: Combined Cassini CAPS and INMS observations, Planet. Space Sci., 57(14-15), 1847-56, doi:10.1016/j.pss.2009.09.006.

Cravens, T. E., et al. (2006), Composition of Titan's ionosphere, Geophys. Res. Lett., 33, L07105, doi:10.1029/2005GL025575.

Cravens, T. E., et al. (2009), Model-data comparisons for Titan's nightside ionosphere, Icarus, 199(1), 174-88, doi:10.1016/j.icarus.2008.09.005

Cui, J., et al. (2009a), Analysis of Titan's neutral upper atmosphere from Cassini ion neutral mass spectrometer measurements, Icarus, 200, 581-615, doi:10.1016/j.icarus.2008.12.005.

Cui, J., M. Galand, R. V. Yelle, V. Vuitton, J.-E. Wahlund, P. P. Lavvas, I. C. F. Müller-Wodarg, T. E. Cravens, W. T. Kasprzak, and J. H. Waite (2009b), Diurnal variations of Titan's ionosphere, J. Geophys. Res., 114, A06310, doi:10.1029/2009JA014228.

Cui, J., M. Galand, R. V. Yelle, J.-E. Wahlund, K. Ågren, J. H. Waite, and M. K. Dougherty (2010), lon transport in Titan's upper atmosphere, J. Geophys. Res., 115, A06314, doi:10.1029/2009JA014563.

De La Haye, V., J. H. Waite Jr., T. E. Cravens, I. P. Robertson, and S. Lebonnois (2008), Coupled ion and neutral rotating model of Titan's upper atmosphere, Icarus, 197(1), 110-36, doi:10.1016/j.icarus.2008.03.022.

Edberg, N. J. T., J.-E. Wahlund, K. Ågren, M. W. Morooka, R. Modolo, C. Bertucci, and M. K. Dougherty (2010), Electron density and temperature measurements in the cold plasma environment of titan: Implications for atmospheric escape, Geophys. Res. Lett., 37, L20105, doi:10.1029/ 2010GL044544.

Ghesquière, P., D. Talbi, and A. Karton (2014), The reaction of the benzene cation with acetylenes for the growth of PAHs in the interstellar medium, Chem. Phys. Lett., 595-596, 13-19, doi:10.1016/j.cplett.2014.01.040.

Hickman, A. P. (1979), Approximate scaling formula for ion-ion mutual neutralization rates, J. Chem. Phys., 70(11), 4872-4878.

Houriet, R., T. A. Elwood, and J. H. Futrell (1978), A tandem ion cyclotron resonance study of the reactions of allyl ions with benzene and substituted benzene, J. Am. Chem. Soc., 100(8), 2320-24, doi:10.1021/ja00476a009.

Lavvas, P., M. Sander, M. Kraft, and H. Imanaka (2011a), Surface chemistry and particle shape: Processes for the evolution of aerosols in Titan's atmosphere, Astrophys. J., 728(2), 80, doi:10.1088/0004-637X/728/2/80.

Lavvas, P., M. Galand, R. V. Yelle, A. N. Heays, B. R. Lewis, G. R. Lewis, and A. J. Coates (2011b), Energy deposition and primary chemical products in Titan's upper atmosphere, Icarus, 213(1), 233-51, doi:10.1016/j.icarus.2011.03.001.

Lavvas, P., et al. (2013), Aerosol growth in Titan's ionosphere, Proc. Natl. Acad. Sci., 110(8), 2729-2734.

Lebonnois, S. (2005), Benzene and aerosol production in Titan and Jupiter's atmospheres: A sensitivity study, Planet. Space Sci., 53(5), 486-97, doi:10.1016/j.pss.2004.11.004

Ma, Y., A. F. Nagy, T. E. Cravens, I. V. Sokolov, K. C. Hansen, J.-E. Wahlund, F. J. Crary, A. J. Coates, and M. K. Dougherty (2006), Comparisons between MHD model calculations and observations of Cassini flybys of Titan, J. Geophys. Res., 111, A05207, doi:10.1029/2005JA011481.

Magee, B. A., J. Hunter Waite, K. E. Mandt, J. Westlake, J. Bell, and D. A. Gell (2009), INMS-derived composition of Titan's upper atmosphere: Analysis methods and model comparison, Planet. Space Sci., 57(14-15), 1895-1916, doi:10.1016/j.pss.2009.06.016.

Mandt, K. E., et al. (2012), lon densities and composition of Titan's upper atmosphere derived from the Cassini lon Neutral Mass Spectrometer: Analysis methods and comparison of measured ion densities to photochemical model simulations, J. Geophys. Res., 117, E10006, doi:10.1029/2012JE004139.

McElroy, D., C. Walsh, A. J. Markwick, M. A. Cordiner, K. Smith, and T. J. Millar (2013), The UMIST Database for Astrochemistry 2012, Astronomy and Astrophysics, 550(A36), doi:10.1051/0004-6361/201220465

Ozturk, F., M. Moini, F. W. Brill, J. R. Eyler, T. J. Buckley, S. G. Lias, and P. J. Ausloos (1989), Reactions of $\mathrm{C}_{5} \mathrm{H}_{3}{ }^{+}$and $\mathrm{C}_{5} \mathrm{H}_{5}{ }^{+}$ions with acetylene and diacetylene, J. Phys. Chem., 93(10), 4038-44.

Rebrion-Rowe, C., L. Lehfaoui, B. R. Rowe, and J. B. A. Mitchell (1998), The dissociative recombination of hydrocarbon ions. II. Alkene and alkyne derived species, J. Chem. Phys., 108, 7185-7189.

Ricca, A., C. W. Bauschlicher Jr., and E. L. O. Bakes (2001), A computational study of the mechanisms for the incorporation of a nitrogen atom into polycyclic aromatic hydrocarbons in the Titan haze, Icarus, 154(2), 516-521.

Smyth, K. C., S. G. Lias, and P. Ausloos (1982), The ion-molecule chemistry of $\mathrm{C}_{3} \mathrm{H}_{3}{ }^{+}$and the implications for soot formation, Combust. Sci. Technol., 28(3-4), 147-54, doi:10.1080/00102208208952550.

Snowden, D., R. V. Yelle, J. Cui, J. -E. Wahlund, N. J. T. Edberg, and K. Ågren (2013), The thermal structure of Titan's upper atmosphere. I: Temperature profiles from Cassini INMS observations, Icarus, 226(1), 552-82, doi:10.1016/j.icarus.2013.06.006.

Vuitton, V., R. V. Yelle, and M. J. McEwan (2007), lon chemistry and N-containing molecules in Titan's upper atmosphere, Icarus, 191(2), 722-42, doi:10.1016/j.icarus.2007.06.023.

Vuitton, V., R. V. Yelle, and J. Cui (2008), Formation and distribution of benzene on Titan, J. Geophys. Res., 113, E05007, doi:10.1029/2007JE002997.

Vuitton, V., R. V. Yelle, P. Lavvas, and S. J. Klippenstein (2012), Rapid association reactions at Low pressure: Impact on the formation of hydrocarbons on Titan, Astrophys. J., 744(1), 11, doi:10.1088/0004-637X/744/1/11.

Waite, J. H., et al. (2005), Ion neutral mass spectrometer results from the first flyby of Titan, Science, 308(5724), 982-86, doi:10.1126/ science. 1110652 .

Waite, J. H., D. T. Young, T. E. Cravens, A. J. Coates, F. J. Crary, B. Magee, and J. Westlake (2007), The process of tholin formation in Titan's upper atmosphere, Science, 316(5826), 870-75, doi:10.1126/science.1139727. 
Wellbrock, A., A. J. Coates, G. H. Jones, G. R. Lewis, and J. H. Waite (2013), Cassini CAPS-ELS observations of negative ions in Titan's ionosphere: Trends of density with altitude, Geophys. Res. Lett., 40, 4481-4485, doi:10.1002/grl.50751.

Westlake, J. H., J. M. Bell, J. H. Waite Jr., R. E. Johnson, J. G. Luhmann, K. E. Mandt, B. A. Magee, and A. M. Rymer (2011), Titan's thermospheric response to various plasma environments, J. Geophys. Res., 116, A03318, doi:10.1029/2010JA016251.

Westlake, J. H., J. H. Waite, K. E. Mandt, N. Carrasco, J. M. Bell, B. A. Magee, and J.-E. Wahlund (2012), Titan's ionospheric composition and structure: Photochemical modeling of Cassini INMS data, J. Geophys. Res., 117, E01003, doi:10.1029/2011JE003883.

Wilson, E. H., S. K. Atreya, and A. Coustenis (2003), Mechanisms for the formation of benzene in the atmosphere of Titan, J. Geophys. Res., 108(E2), 5014, doi:10.1029/2002JE001896.

Young, D. T., et al. (2004), Cassini plasma spectrometer investigation, Space Sci. Rev., 114(1-4), 1-112, doi:10.1007/s11214-004-1406-4. 